Psychother Psychosom 1988;49:60-61

\title{
Thomas Paul Hackett, MD
}

July 6,1928-January 23, 1988

Thomas P. Hackett, Chief of Psychiatry at the Massachusetts General Hospital since 1976 and Eben S. Draper Professor of Psychiatry at Harvard Medical School, died suddenly of an apparent cardiac arrest on Saturday morning, January 23, while horseback riding. He was 59.

Appreciated for his warmth, enthusiasm, sense of humor, and his direct approach to everything, his leadership generated intense loyalty from his department and friends. He had just become the President of the American Academy of Psychosomatic Medicine.

Fascination with nature and biology marked an unusually early start of his scientific career. By age 11 he had his own sizeable snake collection. By age 13, after working with University of Cincinnati Professor of Physiology Gustav Ekstein, he was appointed Instructor of Physiology in the School of Medicine. By 23 he had his MD degree, also from Cincinnati. Work as a Public Health Service physician in several federal penitentiaries, including Alcatraz, awakened an interest in the criminal mind which he pursued for 20 years as a court psychiatrist in Cambridge, Mass. Among the myriad patients seen there were 214 exhibitionists. His intensive study of their dynamics and his treatment proposals reshaped probation guidelines.

Coming to MGH in 1955, he began in 1956 to work as Dr. Avery Weisman's first resident on the newly formed Psychiatric Consultation Service, a service of which he was chief from 1967 to 1977. 'I consider myself first a physician, then a psychiatrist,' he said, describing his particular interest in the interface between psychiatry and medicine. He brought to psychiatric practice a detective's fascination about human behavior. He could look at many a tattoo and detect its port of origin. In addition to his well-known research with cardiac and cancer patients, his writings on hypnosis, pain, amputation, the 'black patch' psychosis, the dying patient, denial, hexing, forensics, and the Amytal interview appeared in 92 professional papers, 49 book chapters, and 3 books. One of the books, the Massachusetts General Hospital Handbook of General Hospital Psychiatry, co-edited by Dr. Ned Cassem, was published in its second edition last year. He had interviewed dozens of World War I pilots, including some of the group known as the Lafayette Escadrille, and was preparing a book on the subject.

For Tom Hackett, life was an adventure shared with his friends.

Obituary

61 


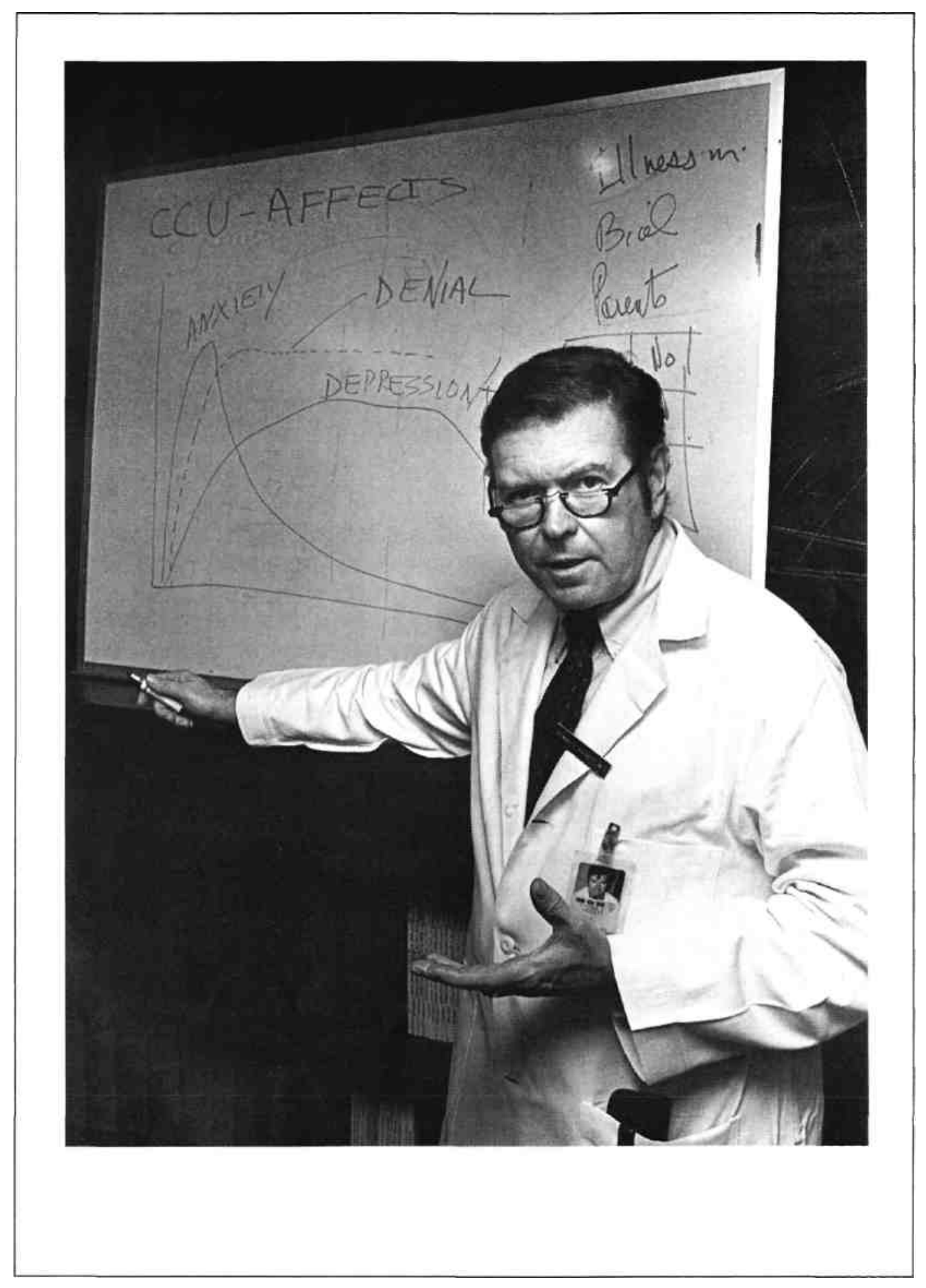

